\title{
A Estrutura Matricial e a Estrutura Sistêmica: Dois Novos Tipos de Organização
}

João Bosco Lodi *

1. Introdução. 2. A Estrutura Matricial. 3. A Estrutura Sistêmica. 4. Conclusão.

A estrutura tradicional da média e grande organização - monística, hierárquica, vertical, piramidal - não parece estar oferecendo condições de flexibilidade e funcionalidade para atender às mudanças do ambiente. De um lado, o alto grau de inquietude entre os administradores revela que os centros de lucro estão mal dimensionados e esmagados pelos centros de custo; de outro lado, no meio acadêmico, a Teoria da Organização Clássica tem sido alvo de críticas e propostas de modificação.

Para examinar o fenômeno do ângulo acadêmico bastaria ler Simon, Thompson, Etzioni, Bennis, Katz e Kahn e recentemente Lawrence-Lorsch, entre outros, para se ter uma idéia da evolução das soluções propostas na segunda parte da década de 1960.

A grande organização partiu de uma estrutura funcional, algumas experimentaram com sucesso a estrutura multidivisional por

* Professor-contratado do Departamento de Administração Geral e Relações Industriais da Escola de Administração de Emprêsas de São Paulo, da Fundação Getúlio Vargas.

R. Adm. Emp., Rio de Janeiro, 10(4): 157-179, out./dez. 1970 
produto, da qual diverge a estrutura do conglomerado, que é mais federativa e independente, para se chegar a uma estrutura multinacional ainda nascente. A organização dos departamentos foi às vêzes substituída por estruturas temporárias chamadas de fôrça-tarefa (wickesberg). Uma proposta recente de Mack Hanan na Harvard Business Review' ${ }^{1}$ tende a apresentar a organização como uma espiral onde as diversas partes, além de se relacionarem entre si, numa base de troca, ligam-se com os elos externos da espiral criando uma segunda ou terceira geração de atividades.

Apenas para mencionar, mas não para abranger um campo tão amplo de hipóteses e experimentações, êste artigo propóe o exame de dois novos modelos de organização: a estrutura matricial $\epsilon$ a estrutura sistêmica. Ambas parecem ter nascido, no ambiente da Administração de Projetos, da Pesquisa Operacional e da Análise de Sistemas. Em ambas é patente a tentativa de resolver o problema da interdependência entre as diversas atividades de uma organização ou da organização com o seu ambiente.

\section{A Estrutura Matricial}

Tradicionalmente, os empresários e organizadores ao tentarem dar uma forma definida ao fluxo de autoridade e de trabalho de suas organizações podiam escolher entre sete tipos de divisão de trabalho ou decidir pela combinação de alguns dêsses tipos: organização por função, por processo, por conhecimento, por clientela, por tempo, por espaço e finalmente por produto. Com o intuito de esclarecer os têrmos poderia dizer que um exemplo de organização por função é: Finanças, Vendas, Produção, Pessoal e Compras. Uma organização por processo é, por exemplo, a da indústria siderúrgica: aciaria, laminação, trefilação. Uma organização por conhecimento predomina na estrutura das escolas superiores: Departamento de Mercadologia, de Produção, de Finanças, etc. Uma organização por clientela é empregada, por exemplo, num departamento de roupas: Homens, Mulheres e Crianças. Há organizações (escolas) que estão divididas em turmas (tempo): manhã, tarde e noite. Assim como

1 BALCÃo, Yolanda F. Organograma, Representação Gráfica da Estrutura. Revista de Administração de Emprêsas, $n^{\circ} 17$, Fundação Getúlio Vargas. 
há pequenos negócios que variam de acôrdo com primavera, verão, outono e inverno. A dimensão espacial ou geográfica tem permitido dividir organizações entre regiões de um todo, seja êle uma cidade, um estado, um país ou o mundo. A organização por produto faz as linhas de autoridade e os fluxos de trabalho estarem subordinados a produtos, grupos de produtos ou marcas.

Apesar de muito antiga, a organização por produto teve uma forma de estrutura mais complexa a partir de 1921 com o aparecimento da estrutura multidivisional por produto, nascida na General Motors e na Du Pont. A organização geográfica tomou uma nova forma, mais recentemente, na corporação multinacional, cujo estatuto jurídico data de aproximadamente 1958.

Pois bem, o objetivo dêste pequeno artigo é informar o leitor sôbre o aparecimento de um nôvo tipo de estrutura, a estrutura matricial. Estou usando êsse têrmo para traduzir matrix orgazation. Evito traduzir literalmente organização de matriz para desfazer uma óbvia confusão. Uma alternativa poderia ser organização em matriz.

Como Chandler já observou em seu precioso estudo, Structure and Strategy, são poucas as oportunidades em que se aplica uma genuína criatividade no processo de elaboração de estruturas organizacionais. No mais das vêzes, o empresário e o organizador dão uma "resposta adaptativa" à necessidade do momento e frequientemente copiam padrões já existentes. A "criação inovadora" é rara em matéria de estrutura de organização.

Um exemplo de criatividade foi a estrutura multidivisional descentralizada que Sloan deu à General Motors em 1921. Imitada mais tarde por inúmeras emprêsas, êsse tipo veio substituir a estrutura funcional multidepartamental, existente no passado de tôdas as grandes organizações industriais.

\subsection{ORIGENS}

O desenho de uma estrutura matricial foi desenvolvido no início da indústria aeroespacial há pouco mais de cinco anos. As novas condições surgidas pelas mudanças levaram à criação de novas relações entre os conceitos e princípios de organização. Uma organização matricial foi criada com a finalidade de estabelecer 
um sistema adaptável de recursos e procedimentos para atingir objetivos de projeto.

O desenho de uma Matriz (Figura 1) pode ilustrar a forma que deu origem a êsse nôvo tipo de estrutura.

Figura 1: Matriz

\begin{tabular}{|c|l|l|l|}
\hline Função & Finanças & Engentiaria & Produção \\
\hline Projeto & & & \\
\hline B & & & \\
\hline C & & & \\
\hline
\end{tabular}

A estrutura matricial nasceu dentro da indústria aeroespacial de par com uma tecnologia altamente sofisticada e uma verdadeira corrida para as realizações científicas. Com o crescimento da especialização do trabalho, a alta tecnologia, a urgência do tempo para conclusão do projeto e o trabalho combinado de várias unidades (emprêsas, órgãos do govêrno, centros de pesquisa) surgiu a necessidade de aumentar o poder do coordenador de projeto. $O$ crescente aumento da autoridade dêsse coordenador foi provando ser uma forma mais eficiente de utilização dos recursos. Com isso o Administrador de Projetos passou a ser uma agência recrutadora e controladora dos recursos aplicados no seu projeto e as áreas tradicionalmente linha passaram a ser subsidiárias do projeto, isto é, prestadoras de serviço.

E preciso entender que essa evolução se deu entre 1958 e 1964, quando os países industrialmente mais avançados passaram a 
participar da corrida espacial, entrando num tipo de indústria muito mais sofisticado e num tipo de aceleração de desenvolvimento muito mais crucial do ponto de vista da liderança mundial. Não se tratava, pois, da organização tradicional com linhas de produto estabelecidas, canais de autoridade e fluxos de trabalho determinados há mais tempo. O modêlo de uma organização matricial está exemplificado na Figura 2.

Figura 2: Organização Matricial

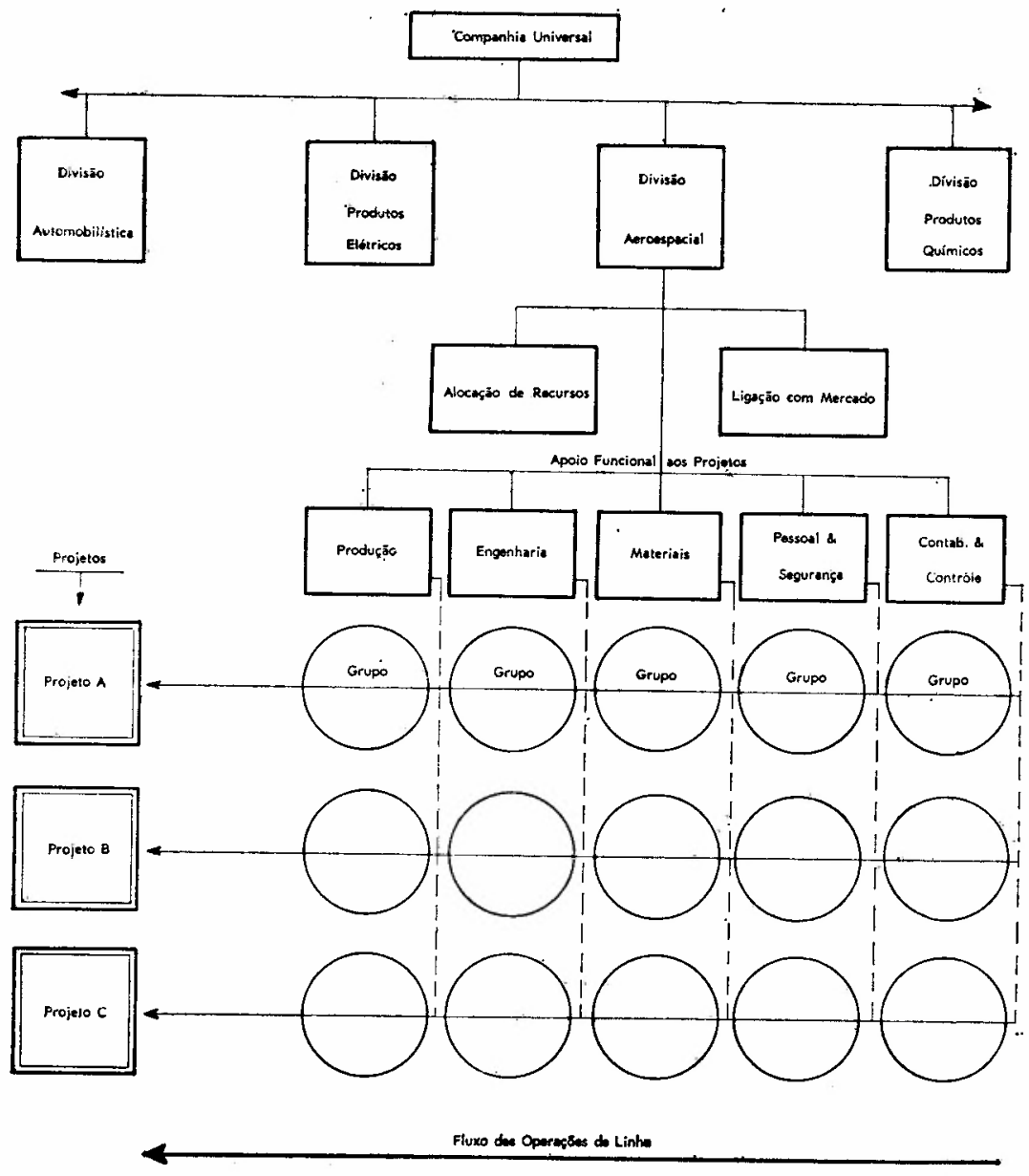




\subsection{O TIPO TRADICIONAL E O NÔVO}

O tipo tradicional de organização permite um fluxo de trabalho através de unidades funcionais autônomas:
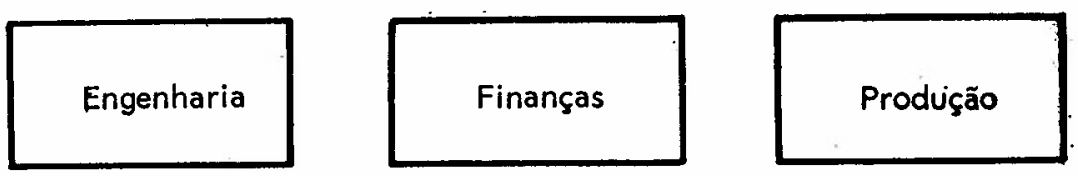

Um gerente de Divisão é totalmente responsável pelos programas de trabalho dos produtos de sua divisão. Na organização matricial, o gerente de divisão tem a mesma responsabilidade e autoridade sôbre os resultados. Há, porém, diferenças na divisão de trabalho. Quando o trabalho é aplicado a produtos ou serviços estandardizados em alta escala não há necessidade da organização matricial. O fluxo de trabalho se dá através de cada divisão ou do grupo de divisóes até o mercado. A ênfase é dada na eficiencia dêsse fluxo de trabalho.

Porém, quando o trabalho passa a ser realizado para contratos de projetos específicos, a organização matricial passa a ser empregada eficientemente. A ênfase deixa de ser dada no volume contínuo de produção e passa a ser colocada na complementação do trabalho para um projeto específico. $O$ tipo matricial de organização é construído para projetos específicos. Um gerente recebe autoridade e responsabilidade para completar seu projeto em tempo, custo, qualidade e quartidade especificados nos contratos. A organização de linha se desenvolve a partir do projeto, tornando as funções anteriormente consideradas linha (produção, engenharia, finanças), apenas funções de serviço e de apoio ao projeto.

\subsection{O GERENTE DE PROJETO}

Numa breve notícia numa revista de administração, eis o que diz John Mee: "O gerente de projeto recebe o pessoal com as qualificações essenciais para os departamentos funcionais enquanto durar o projeto. Portanto, a organização de projeto é composta de um gerente e de grupos de pessoal funcional. Com a responsabilidade pela execução completa e bem sucedida do con- 
trato, o gerente de projeto tem autoridade sobbre o planejamento do trabalho, a designação de pessoal para os grupos funcionais e a determinação do relacionamento entre os grupos funcionais. Tem autoridade para recompensar o pessoal com promoções, aumentos salariais e outros incentivos enquanto o projeto estiver avançando. Tem também autoridade para liberar pessoas dos compromissos designados nos diversos grupos funcionais. Quando o projeto estiver terminado, o pessoal do grupo funcional volta aos departamentos funcionais de origem, para redesignação de tarefas ou para transferência a outras divisões ou para programas de treinamento. $O$ gerente de projeto também poderá ser removido para outras atividades".

\subsection{OBJETIVOS E RELACIONAMENTO}

O método de administração que melhor se coordena com o modo de agir de uma organização matricial é a administração por objetivos de projeto. Enquanto cada grupo funcional cumpre seu trabalho, o pessoal dos departamentos funcionais dá apoio e assistência aos projetos, na forma de orientação política, orientação técnica e serviços administrativos. As operações de linha são ilustradas horizontalmente e as operações de apoio funcional verticalmente passando pelos diversos projetos em andamento. O conceito da organização matricial é um sistema chamado teia de relações, em vez do sistema linha-staff das organizações tradicionais.

\subsection{VANTAGENS}

Os administradores norte-americanos têm um orgulhoso registro de engenhosidade em criar novos esquemas organizacionais para se adaptarem a requisitos técnicos e econômicos em constante mudança. A organização matricial é um dêsses esquemas engenhosos. Ela permite um alto grau de especialização com o máximo de eficiência nas operações. Dentro dêsse esquema, desenvolvem-se novas técnicas de administração de sistemas, economia da informação e sistemas de informação, além de aperfeiçoamento dos sistemas de planejamento e contrôle da produção. 


\subsection{PESSOAL}

E claro que as pessoas que trabalham nesses novos ambientes de organização precisarão ter novos conhecimentos e habilidades. Trabalhar em ambientes que se caracterizam por contínuas mudanças, como o dos projetos, requer capacidade de adaptação e não é tão seguro e confortável como trabalhar numa função tradicional em que as mudanças são poucas.

\subsection{APLICAÇÕES}

Apesar de a organização matricial ter surgido na indústria aeroespacial, pode-se pensar que o conceito pode ser aplicado a outras indústrias onde predomina o desenvolvimento de novos produtos numa economia dominada pelo marketing. Tenho notícia de que a Procter and Gamble, nos Estados Unidos, está experimentando essa nova estrutura num ramo (food business) altamente competitivo e renovado.

Creio poder concluir dizendo que tôda vez que a cordenação de um produto ou atividade entre diversas áreas mais ou menos estanques é vital para a sobrevivência da organização, o coordenador dêsse produto tende a elevar o seu status e poder em nivel igual ou superior ao das áreas prestadoras de serviço. ${ }^{2}$

\section{A Estrutura Sistêmica}

A Teoria de Sistemas está produzindo esquemas teóricos e operacionais mais adequados à realidade da interdependência entre as partes do todo da organização e dela para com os seus diversos ambientes; a Teoria de Sistemas aborda a organização como um conjunto de unidades internas e externas integradas num todo. Durante muitos anos a Teoria de Administração estêve preocupada com temas, hoje quase esgotados, como o da autoridade hierárquica, deixando obscuras as relações entre as diversas unidades. Há um decênio, Harold Leavitt falava no supervisor como um linking pin (um pino de ligação) entre as partes do todo. Mais recentemente, apareceu um estudo sistemático dês-

2 Bertalanffy, Ludwig von. General System Theory: a New Approach to Unity of Science. Human Biology, dezembro de 1951, p. 303-361; e BouLDING, Kenneth. General Systems Theory: the Skeleton of Science. Management Science, abril de 1956, p. 197-208. 
ses dispositivos de ligação (linkage devices) entre as partes. A Engenharia dos Sistemas é quem vem contribuindo de maneira notável para explicitar essas relações e dispositivos de ligação.

Nesta parte do capítulo procurarei analisar a transição do organograma tradicional para as novas formas de organograma que permitem maior visão do relacionamento. Neste ponto, apoiarme-ei principaimente no trabalho de Cleland. ${ }^{3}$

\subsection{ORGANOGRAMA TRADICIONAL}

O organograma tradicional surgiu, segundo explica Ernest Dale em The Great Organizers, no trabalho dos pioneiros da Administração, Poor e McCaluum. Esses dois engenheiros ferroviários e diretores da Pennsylvania Railroad publicaram os primeiros organogramas por volta do fim do primeiro quarto do século passado. O organograma primitivo imitava uma árvore genealógica e portanto tinha o fluxo de autoridade de baixo para cima; na raiz da árvore estava o fundador, no tronco o diretor-presidente em exercicio e nos ramos principais, os diretores ou membros da família com funções diretivas.

Daí em diante, o organograma tomou várias formas como observa Yolanda F. Balcão, ${ }^{4}$ mas manteve o sentido piramidal e monocrático que o caracteriza ainda hoje. Esse organograma parece fornecer apenas três informações: a) quem faz cada tarefa, b) quais são as linhas de autoridade hierárquica ou quem é o superior imediato de cada pessoa, e c) quais são as funções reunidas sob a mesma área, departamento ou divisão. Obter do uso de um organograma apenas essas três informações é obter muito pouco. O organograma não informa, por exemplo, as interdependências entre as várias areas, o grau de autoridade que cada executivo exerce, os limites de atuação entre subordinado e superior, e, o que é mais grave ainda, não informa sôbre as tarefas e responsabilidades que cabem a cada executivo. Por consequiência, o organograma precisa vir acompanhado de um Manual de Organização contendo descrições de cargos. Esses manuais, além

3 Cleland \& KIng. Systems Analysis and Project Management. Nova Iorque, McGraw-Hill, 1968, capitulo 9 (The Organizational Chart: a Systems Viewpoint). Neste capítulo estão indicadas as fontes onde os autores se apoiaram.

4 HANAM, Mack. Corporate Growth through Internal Spin-Outs. Harvard Business Review, novembro/dezembro de 1969. 
de volumosos, são muitas vêzes obscuramente intrincados, difíceis de serem refeitos na velocidade necessária e portanto tornam-se fàcilmente obsoletos, como a maior parte dos que se vê nas organizações de hoje.

\subsection{O ORGANOGRAMA LINEAR}

Uma tentativa de conciliar as vantagens do organograma clássico com as descrições de cargo que compõem o Manual de Organização foi apresentada no Organograma Linear (Figura 3). O Organograma Linear relaciona na coluna vertical do lado direito lista das tarefas ou atividades numa determinada divisão ou parte da emprêsa. Relacionada com essa coluna vertical, uma linha horizontal indica todos os cargos intervenientes naquela divisão ou parte da emprêsa. Forma-se assim uma matriz contendo cargos e atividades. Finalmente, mediante um sistema de codigos ou símbolos, indica-se o grau de autoridade e a relação entre cada cargo e cada atividade. Por exemplo: se a pessoa executa aquela atividade, se é responsável pela supervisão, se deve ser notificada, etc.

A leitura do Organograma Linear nos dá diversas informações. Se precisarmos saber sôbre as tarefas de cada pessoa, basta lermos o organograma verticalmente na coluna em que a pessoa (ou cargo) está mencionada. Se precisarmos saber quais as relaçóes ou interdependências criadas por uma tarefa ou atividade no conjunto dos cargos da emprêsa, basta lermos o organograma horizontalmente na linha referente àquela atividade.

o Organograma Linear apresenta duas vantagens sôbre a Descrição de Cargos: a) as Descrições de Cargos são melhores ao descrever responsabilidades, do que ao retratar as relações e interdependências nos diversos cargos; b) o Organograma Linear apresenta a emprêsa como um sistema integrado em vez de uma série de cargos individuais. Mais do que clarificar as relações de autoridade, o Organograma Linear pode substituir as descrições de cargo.

Apesar dessas vantagens, o Organograma Linear não mostra como as pessoas trabalham e interagem, o que é extremamente importante para as tarefas que são executadas em comum numa rêde de atividades combinadas. 
Figura 3: Organograma Linear

Estabslece Politicas e Objetivos Básicos

Dirige Funç̃es de Operação, Planejamento e Contrôle

Fixa as Reboçōes Entre Escritório Central a Divisöes

Controla Planos de Expansão, Fusäo e Aquisiçăo

Administra Operaçōes de Fusão • Aquisiçăo

Estabeloce Politicas e Procedimentos de Marketing

Coordena Previsöes de Vendas

Coord. Planos de Propaganda

Coord. Engentraria, Pesquisa a Desenyolvimento

Coord. Programas de Novos Produtos

Admininstra Centro de Pesquisa a Desenvolvimento

Estabelece Politicas e Procedimentos Contábeis

Administra Financiamento e Crédito

Coordena Orçamentos

Administra Assuntos Legais a Fiscois

Utilizaçäo de Facillidades industriais

\begin{tabular}{|c|c|c|c|c|c|c|c|}
\hline 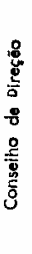 & $\begin{array}{l}\frac{2}{5} \\
\frac{8}{8} \\
\frac{8}{2} \\
\frac{2}{2}\end{array}$ & 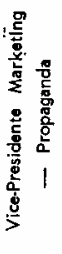 & 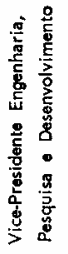 & 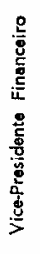 & 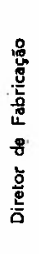 & 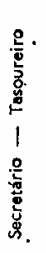 & 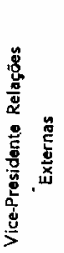 \\
\hline 2 & 1 & 3 & 3 & 3 & 13 & 3 & 3 \\
\hline 2 & 1 & 4 & 4 & 4 & 4 & 4 & 4 \\
\hline 2 & 1 & 3 & 3 & 3 & 3 & 3 & 3 \\
\hline 2 & 1 & 3 & 3 & 3 & 3 & 3 & 3 \\
\hline & 2 & 1 & 3 & 3 & 3 & 3 & 3 \\
\hline & 2 & $i$ & & 4 & & & 4 \\
\hline 5 & 2 & 1 & & 5 & & & 3 \\
\hline 5 & 5 & 1 & & & & & 4 \\
\hline 5 & 2 & 3 & 1 & 4 & 4 & & 4 \\
\hline & 2 & 3 & 1 & 4 & 3 & & 4 \\
\hline & 3 & & 1 & & & & \\
\hline & 2 & & & 1 & & & \\
\hline 2 & 2 & & & $I$ & & 3 & \\
\hline 5 & 2 & 3 & 4 & 1 & 3 & & \\
\hline & 2 & & & 1 & & & \\
\hline & 3 & & & & 1 & & \\
\hline
\end{tabular}

I Responsável pela Execução

2 Supervisăo

3 Precisa ser Consultado

4 Pode ser Consultado

5 Precisa ser Notificado 


\subsection{DO ORGANOGRAMA LINEAR AOS ESQUEMAS SISTÊMICOS}

A conexão e a operação sistemática das partes de um todo é o próximo passo de nossa intervenção. Se as formas até agora vistas ainda não foram suficientes para retratar êsse tipo de relacionamento, examinaremos como o assunto tem sido abordado na Teoria de Sistemas.

Os sistemas humanos, apesar de desenhados, numa analogia dos sistemas mecânicos ou eletrônicos de engenharia, são sistemas abertos. O sistema do engenheiro é fechado porque só pode produzir as saidas especificadas quando tôdas as condições e fatôres foram previstos e nenhuma outra condição ou fator veio interferir. Esse tipo de sistema não funciona, seja quando o fornecimento de energia não atinge o nível requerido, seja quando as entradas são maiores do que o previsto, seja quando o ambiente é mais severo do que se supunha, seja quando uma das partes mudou de características; pois o sistema fechado tem como fatôres principais a previsibilidade e a conformidade.

Pelo contrário, um subsistema de trabalho é aberto porque os componentes são pessoas humanas não programadas e porque os riscos e incertezas não podem ser totalmente abrangidos na previsão. Por isso, os subsistemas de trabalho humano aproximam-se mais dos modelos biológicos do que dos modelos físicos. ${ }^{5}$

Tentemos, então, passar dos conceitos abordados acima para um diagrama que retrate as relações horizontais e verticais entre os membros de uma organização de trabalho. Os cargos e pessoas que intervêm no diagrama são apenas os mais importantes; foram deixadas de lado as funções como as de secretária, desenhista ou auxiliar para maior simplicidade do esquema.

Partindo da Figura 3 onde aparece um trecho do Organograma Linear retratando as atividades da Diretoria, vamos examinar um grupo de técnicos envolvidos na atividade de contrôle de qualidade. Trata-se de uma Divisão de Testes de Equipamentos, com-

- MEE, John F. Matrix Organization. Business Horizons, University of Indiana, junho de 1969 .

Miller. Cost, Schedule, Control and PERT Systems, 1963. 
posta de um departamento de Coordenação e um departamento de Operação dos Testes. Este último divide-se em três seções: 1. de Dados e Análise, 2. de Testes Eletro-Mecânicos, e 3) de Testes Eletrônicos.

O problema consiste em definir quem e como intervém na atividade de redigir procedimentos para Testes de Material. Um organograma clássico mal esclareceria essa questão. Vejamos como a Teoria de Sistemas pode ajudar-nos.

Usando o Organograma Linear (Figura 3) podemos imaginar uma coluna vertical à esquerda, onde estão apontadas as atividades dessa Divisão, entre as quais a de redigir procedimentos para Testes de Material. A linha horizontal no tôpo do organograma linear indicará tôdas as áreas ou cargos intervenientes.

Como êsse ponto de partida produzimos a Figura 4 que indica o aparecimento da função transformadora (redige procedimentos) e o modêlo de entrada e saída. Da Figura 4 passamos à Figura 5, onde a tarefa redigir etc., é colocada no centro de um esquema sistêmico em que as Entradas e Saídas são constituídas das seções que participam no fornecimento ou no recebimento de dados. A Figura 6 desenvolve o esquema completo da atividade em estudo.

O diagrama proposto oferece as seguintes vantagens:

1. As tarefas e atividades do subsistema de trabalho são alistadas de acôrdo com um fluxo funcional de trabalho.

2. Os cargos intervenientes mantêm sua identidade própria, como no organograma clássico, e ficam separados por colunas alinhadas de acôrdo com as divisões administrativas.

3. Os símbolos dentro de cada caixa indicam o tipo de interdependência existente entre as várias áreas.

4. O modêlo total permite ver em perspectiva como a organização formal estática combina com o subsistema de trabalho numa entidade dinamica. 
Figura 4: Modêlo de Entrada e Saída e Aparecimento da Função Transformadora

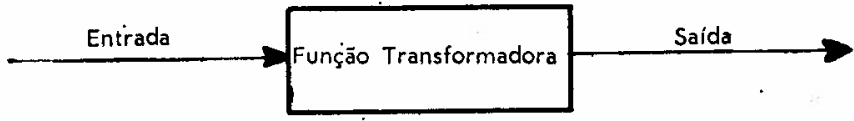

Modêlo Básico de Entrada-Saida

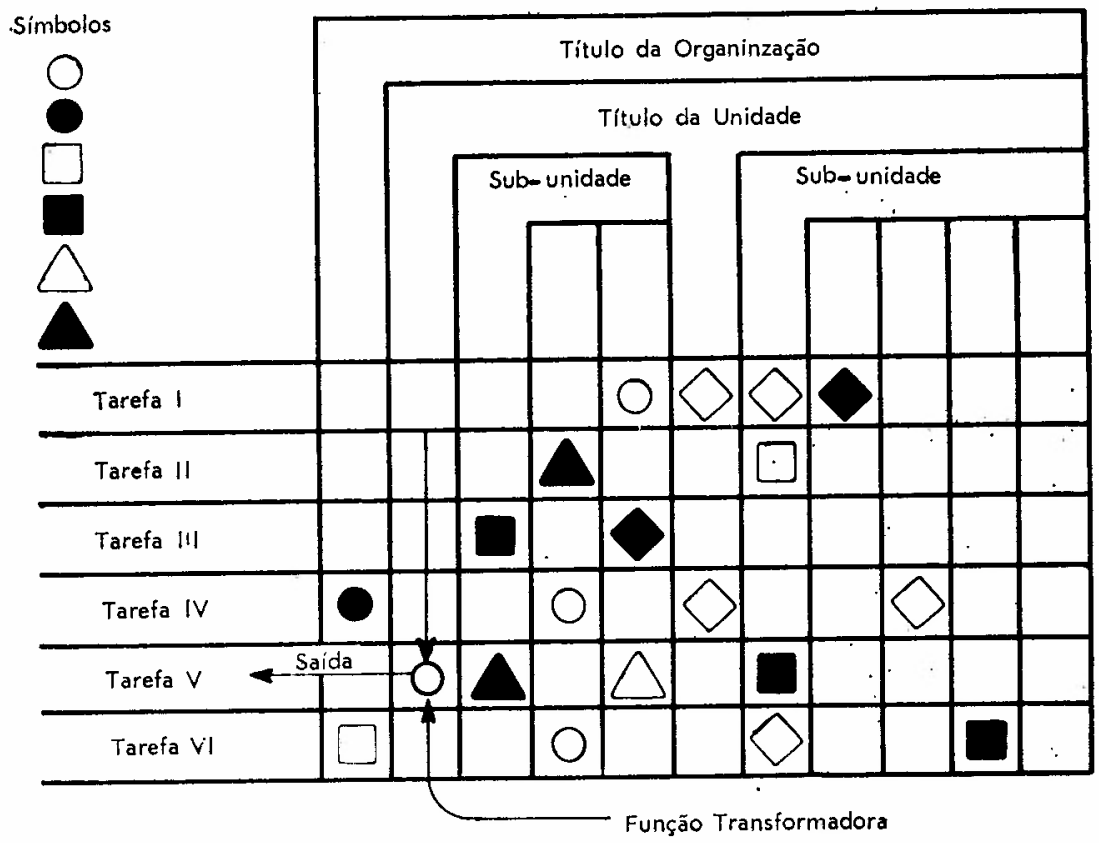

Figura 5: Formato Esquemático do Modêlo de Sistemas

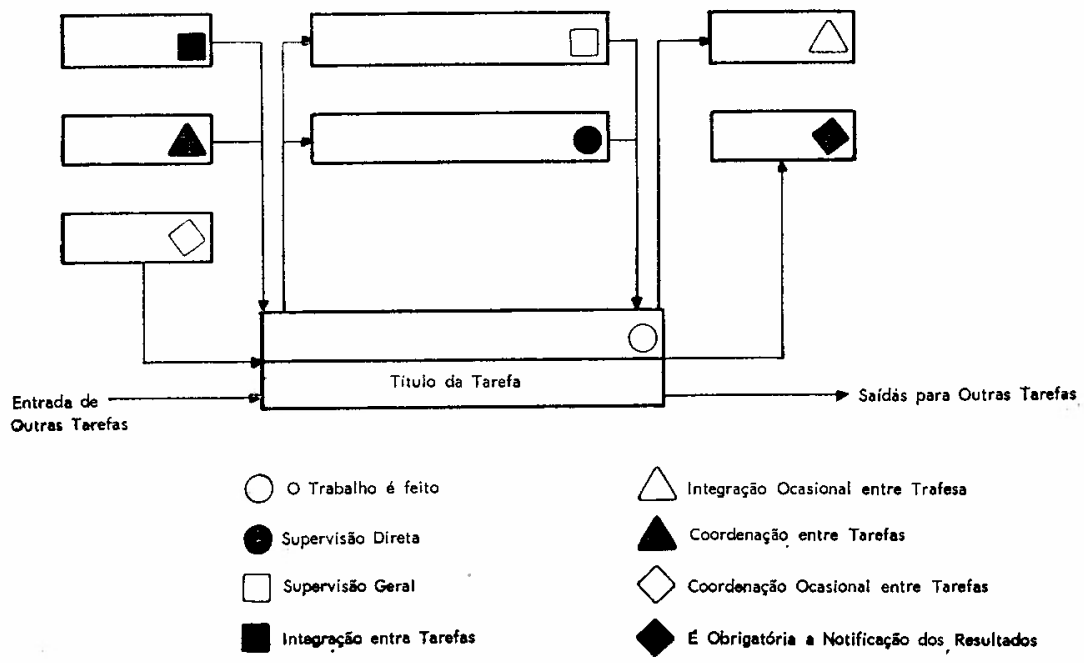




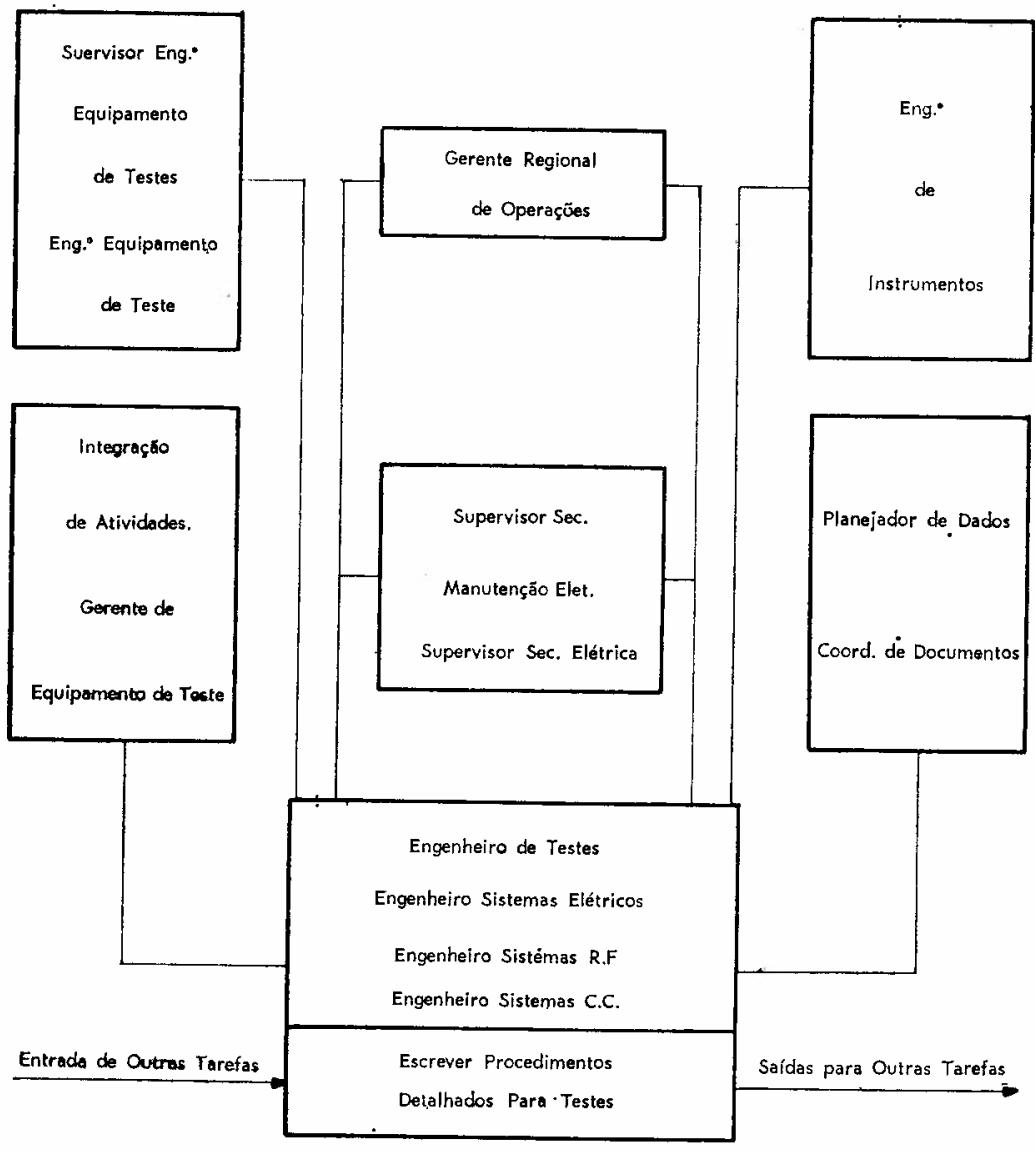

0

O Trabatho é Feito

Supervisäo Direta

$\square$ Supervisão, Geral

Integraçso Entre Tarefas $\bigwedge$ Integraçăo Oçasional entre Tarefas

A Coordenação entre Tarefas

Coordenaçăo Ocasional entre Tarefas

E Obrigatória a Notificação dos Resultados 
Figura 7: Integração do Trabalho e dos Subsistemas Administrativos numa Organização

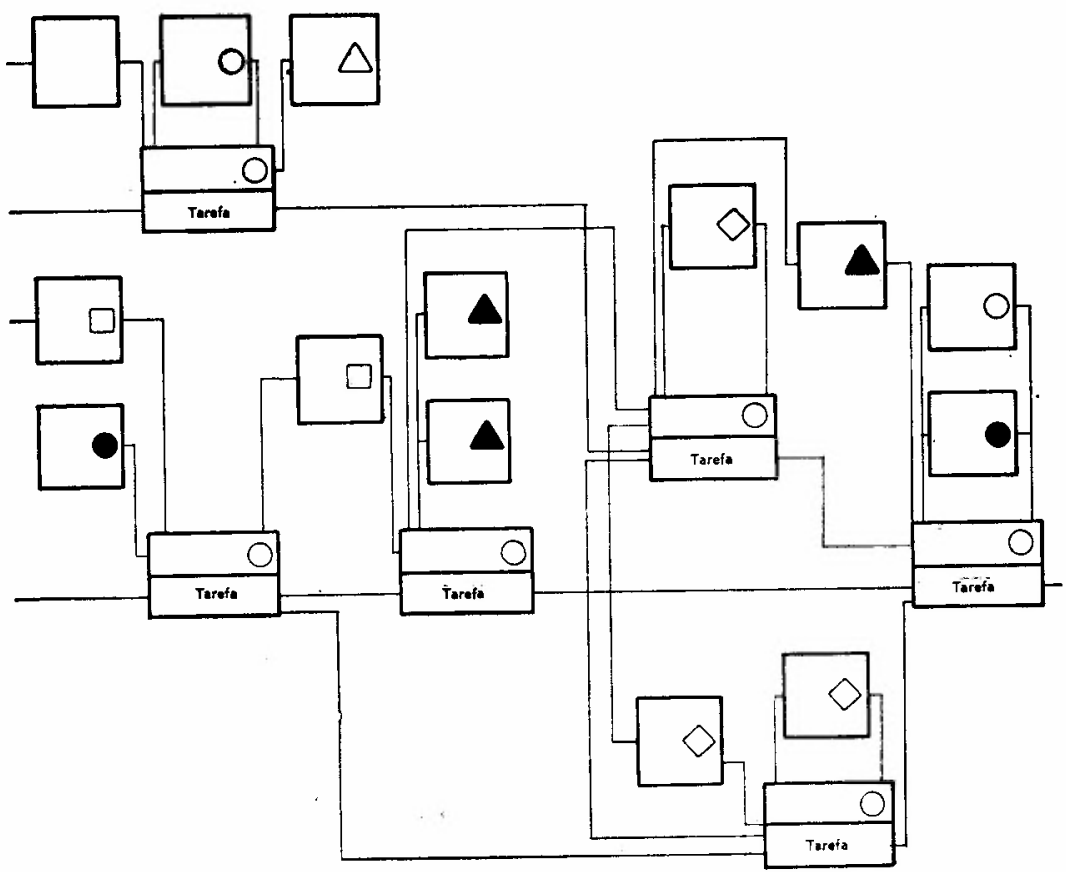

\section{CONCLUSÃo}

Nos dois modelos examinados, concluímos que as relações hierárquicas e verticais de autoridade não são suficientes para ajudar a compreender tanto as interdependências internas entre as partes da organização, como o atendimento das solicitações ambientais. E, em ambos os casos o relacionamento lateral ou horizontal aumentou e a organização descobriu sua dimensão horizontal. Nos dois esquemas, a autoridade hierárquica tradicional está subentendida, mas fora de foco, vagamente descrita ou ausente, se bem que dentro de cada grupo existam e permaneçam eficientes as curtas linhas de autoridade operativa. Em 1966 o professor francês Octave Gelinier propunha para as organizações tradicionais francesas que encurtassem as linhas hierárquicas reduzindo com isso a demora nos estágios da decisão e tornando a estrutura mais flexível e rápida nas respostas. 
$\mathrm{Na}$ estrutura matricial a função do Diretor de Projeto tende a aumentar de importância e a se diferenciar das funçóes dos departamentos ou divisões tradicionais, de modo a assegurar maior autoridade e poder de comando para a defesa dos interêsses do cliente no que respeita à coordenação entre atividades diferentes junto a um mesmo projeto.

$\mathrm{Na}$ estrutura sistêmica, as relações entre as partes são estudadas e definidas da maneira mais clara e formal, assegurando vínculos c dispositivos de ligação definidos, de modo também a assegurar o fluxo contínuo das operações.

Pelo que ficou demonstrado até agora, torna-se bem patente que as novas colocações da Teoria da Organização, especialmente as da Teoria de Sistemas, constituem uma oposição à visão clássica da organização. A concepção da emprêsa como sistema envolve uma modificação do conceito clássico, expresso pela teoria funcionalista: a firma era vista como uma estrutura composta de funções como comercialização, produção, finanças, engenharia, etc. Essas funções justapostas e mal integradas dificilmente podem conviver com a abordagem sistêmica.

A introdução de processamento eletrónico de dados na firma de hoje é o exemplo da inadequação do conceito funcional. Enquanto o processamento de dados apenas exercia atividades circunscritas e isoladas, pràticamente replicando o trabalho de um indivíduo ou departamento, êle se enquadrava na estrutura funcional. Mas a partir do momento em que o processamento de dados passou o seu estágio de guarda-livros para produzir o sistema de Informação Administrativa (MIS), os rígidos compartimentos da estrutura funcional passaram a constituir um sério obstáculo. O funcionalismo tende a separar as atividades, levantar muros e concentrar cada função em seus subobjetivos.

O exemplo pode ser visto na atividade da Administração de Inventários. O Departamento de Comercialização tende a manter grandes estoques de produtos acabados para atender ràpidamente à entrega. O Departamento de Produção não está interessado em estocar produtos acabados, mas tende a manter grandes estoques de materiais e suprimentos para garantir o fluxo da produção. O Departamento Financeiro tende a defender o capital de 
giro minimizando o investimento nos estoques. O Departamento de Compras está interessado em fazer determinados negócios de oportunidade que se refletem em níveis superados de certos estoques, criando problemas para a prōdução. Enfim, os diversos departamentos funcionais subotimizam pela otimização de seus próprios objetivos, criando barreiras e tendendo a digladiar-se entre si.

Mas os males da teoria funcionalista não ficam só até aí. Há a inadequação dos diversos princípios de organização: a amplitude de contrôle, a unidade de comando, a dicotomia linha-staff, e outros. A amplitude de contrôle (span of control), para reduzir a carga de trabalho dos diversos executivos, aumentar os niveis hierárquicos criando mais estágios para a decisão, longas linhas hierárquicas, rigidez e excessiva burocracia. A unidade de comando torna difícil a ação dos agentes de mudança porque a autoridade é detida pela hierarquia, com desvantagem para os profissionais do conhecimento. A dicotomia dos conceitos de linha e staff torna difícil a colaboração nos pontos de decisão.

A teoria clássica da organização, aqui chamada de funcionalista, tirou sua forma de duas organizações antigas: a Igreja Católica e os exércitos tradicionais, organizações essas, rígidas, hierárquicas e especialmente não-sistêmicas. Apesar dessa teoria clássica ter contribuido como um estudo anatômico para tirar a organização industrial do caos primitivo, ela está hoje bastante incapacitada para atender à agilidade, flexibilidade e rapidez de mudança que se requer numa época de mudanças.

COMENTÁRIOS AO ARTIGo "A ESTRUTURA MATRICIAL E A ESTRUTURA SISTÊMICA: DOIS NOVOS TIPOS DE ÓRGANIZAÇÃO"

\section{Alysson Darowish Mitraud}

Entendo que o Prof. Lodi esteja a sugerir que a chamada organização matricial (ou estrutura matricial) seja uma "criação inovadora"; tal conclusão não fica tão clara quando o mesmo pretende estabelecer as diferenças que deveriam ser substanciais entre o tipo tradicional de organização e o matricial. Na verda- 
de, pode-se quase que perceber, nesse esforço, as características diferenciadoras entre organização por propósito e por processo, ambas tradicionais. Nesse sentido, a estrutura matricial me parece mais uma adaptação do que algo realmente nôvo. Com essa conclusão, é necessário que o autor esclareça qual realmente o sentido dêsse aperfeiçoamento, em têrmos de estrutura, já que a organização por propósito também se propunha aos mesmos objetivos.

No meu modo de entender, a filosofia dêsse tipo de estrutura é mais uma resposta à perda de eficiência, causada pela maximização de subobjetivos que a organização burocrática apresenta, quando a autonomia dos departamentos funcionais os leva a se distanciarem dos objetivos da organização, o que, aliás, se menciona na conclusão do artigo.

Ao pretender resolver os problemas criados, ao longo do tempo, pela estrutura burocrática (maximização de subobjetivos), não estaria a estrutura matricial, com o coordenador de projetos, reeditando o modêlo autocrático de chefia, ao atribuir ao coordenador podêres excepcionais? Se isso fôr verdade ou não, quais deveriam ser as características e qualificações dêsse coordenador? Imaginando que, na chamada era tecnocrática, aos especialistas se atribui soma crescente de prestígio e poder, êsse tipo de estrutura não apresentaria, com o tempo, as mesmas deficiências da burocracia, que também não foi idealizada para maximizar subobjetivos?

Essas questões são um exemplo do que, a meu ver, deveria integrar o artigo; isto é, uma análise crítica, de eficácia relativa, dêsse tipo de estrutura - que pretende solucionar velhos problemas - e dos eventuais problemas que podem surgir da sua aplicação.

Na parte relativa à "estrutura sistêmica", o autor combina os pressupostos básicos da teoria de sistemas com esquemas de funcionamento de organizações onde, grâficamente, isso se representa. $O$ "organograma linear" é apresentado à guisa de um estágio intermediário, nos estudos de estrutura, entre a estruturação clássica e a sistêmica. Cumpre, nesse ponto, um parêntese: existiria uma estrutura sistêmica, isto é, uma estrutura sis- 
têmica de organização, em oposição às antigas formas, ou por estrutura sistêmica se entende um modo de abordagem às organizações, enquanto subsistemas de sistemas maiores?

No que diz respeito ao organograma linear, êste, ao invés de parecer-me substitutivo dos organogramas clássicos, dos manuais de organização e das descrições de cargos, é mais um resumo das atribuições dos cargos de uma organização e, como tal, está longe de resolver os problemas básicos que aquêles instrumentos apresentam. E verdade que, para certas finalidades, como a visualização de um processo qualquer, onde há mais informações e inter-relacionamentos que no organograma clássico, e menos palavras que nos manuais de organização que tentam ser exaustivos, êle é indiscutivelmente útil. Contudo, êle dependeria da habilidade dos técnicos, em organização, de prever $\epsilon$ formular, na coluna da esquerda, as atribuiçóes que realmente são as mais importantes e de descartar as irrelevantes. Se um número muito grande de atribuições aparece formulado em frases longas e cheias de detalhes, a vantagem desaparece.

Quanto aos esquemas sistêmicos apresentados pelo Prof. Lodi, antes de significarem um avanço nos modos de estruturação, nodem representar destaques nos processos operacionais, em que as atividades de certas unidades são diagramadas para atender à possibilidade de compreensão dos analistas de sistemas e programadores. Outro exemplo disso seria a montagem de problemas estatísticos por diagramas de blocos, para que o programador que não conheça bem a estatística, possa realizar o seu trabalho. E claro que essas considerações não se dirigem ao autor do artigo, mas aos procedimentos em si. Porque não vejo como êsses procedimentos, por si sós, conseguiriam superar, ou mesmo minimizar, os problemas de estrutura das organizações que, no meu entender, são muito mais amplos e complexos que aquilo que essas técnicas podem alcançar.

No meu entender, a limitação que o artigo apresenta, na sua primeira parte, aparece também na segunda: o Prof. Lodi se limitou a apresentar os instrumentos, sem contudo analisar-lhes as potencialidades e limitações. 


\section{João Bosco Lodi}

O Prof. Mitraud sugere que eu estabeleça diferenças entre o tipo tradicional de organização e o tipo matricial. Essas diferenças estão já expostas no artigo, sob o título $O$ Tipo Tradicional e o Nôvo.

Mais adiante, o Prof. Mitraud evoca uma identidade da organização matricial e a organização por propósito. A meu ver não há confusão entre ambas. A organização por propósito, tal como foi definida na obra clássica de Gulick e Urwick em 1937, agrupa tôdas as atividades relacionadas ao mesmo fim comum sob um mesmo comando. Mas êsse agrupamento por propósito comum é por tempo ilimitado, com tôdas as caracteristicas de uma departamentalização fixa, não havendo ligação dessas atividades com outras atividades dentro da organização. Era como se a emprêsa fôsse organizada na base de subemprêsas sem apoio de serviços centrais. Diferentemente dêsse tipo de organização, a organização matricial estabelece que: a) a organização é por projetos, b) cada projeto agrupa diversas fôrças-tarefas recrutadas dos departamentos de serviço originais, c) a duração de cada projeto e, portanto, de cada fôrça-tarefa é limitada à duração do contrato e do cronograma, d) tôda a organização é, portanto, provisória e temporária, e) e finalmente mantém-se definida uma relação de linha-staff com os departamentos de apoio, tal como aparece na Figura 2.

A inquietude do Prof. Mitraud quanto ao estilo de liderança não me parece fundada. $O$ estilo de liderança não guarda relação com o tipo de estrutura global adotada. $O$ tipo de estrutura adotado poderá criar problemas de coordenação, integração e diferenciação, mas certamente não influirá muito sôbre o estilo em si. Êste é influenciado por outras variáveis: a personalidade do líder, o tipo de grupo a ser liderado, a situação, as caracteristicas da tarefa. A meu ver, a liderança a ser exercida na estrutura matricial, tal como em qualquer outro tipo de estrutura, está ligada a essas variáveis humanas e grupais. 
Quanto à questão das características do coordenador do projeto, esta já está analisada no artigo, sob o título $O$ Gerente de Projeto.

Meu crítico mais adiante, indaga se a estrutura matricial não apresentaria com o tempo as mesmas deficiências da burocracia. A estrutura matricial também está sujeita às disfunções burocráticas. Se, de um lado, ela visa a evitar a maximização de subobjetivos funcionais, ela criará outras dificuldades, pois o projeto tenderá a concorrer com os outros da mesma organização, quanto a utilização dos recursos físicos, financeiros e humanos. Quero dizer que o projeto tenderá a maximizar seus subobjetivos em detrimento dos (ou concorendo com) outros projetos.

Quanto à análise crítica da eficácia dêsse tipo de estrutura que, no entender do Prof. Mitraud, deveria integrar o artigo, esta é uma questão muito complexa para ser analisada agora, no momento em que êsse tipo de organização ainda está nascendo. Os modelos matriciais em funcionamento nos Estados Unidos (aproximadamente 48 organizações) ainda são experimentais, não havendo dados suficientes para uma avaliação de um desempenho. Qualquer outra antecipação seria superficial.

O Prof. Mitraud indaga se "existiria uma estrutura sistêmica, isto ê, uma estrutura sistêmica de organizações, em oposição às antigas formas, ou por estrutura sistêmica se entende um modo de abordagem às organizações, enquanto subsistemas de sistemas maiores". Estou distinguindo abordagem (ou método) sistêmica, da estrutura sistêmica. A abordagem é uma maneira de analisar e foge ao âmbito do artigo. Estou usando o têrmo estrutura sistêmica para me referir ao modo, forma ou arranjo pelo qual as fomas são agrupadas e relacionadas entre si.

Diz ainda o Prof. Mitraud quanto aos esquemas por mim apresentados que "antes de significarem um avanço nos modos de estruturação, podem representar destaques nos processos operacionais, em que as atividades de certas unidades são diagramadas..." Estou de acôrdo que os esquemas sistêmicos foram no início uma técnica de análise operacional a nível de execução. Porém, com o passar do tempo, êsses esquemas foram sendo 
aplicados mais amplamente até o ponto de diagramar tôda a organização. É uma proposição da Teoria de Sistemas que a organização é um sistema de informação.

Pouco adiante afirma o crítico: "não vejo como êsses procedimentos (de sistemas) conseguiriam superar os problemas de estrutura de organização, que, a meu ver, são muito mais amplos". Esta questão pede uma resposta demasiado difícil para o autor. E difícil prever como êsses esquemas conseguiriam superar etc. Porém na própria exposição da segunda parte, procuro mostrar que um desenho sistêmico ajuda a entender a interligação das diversas áreas em cada núcleo decisório principal, havendo nesses pontos nodais uma boa ligação entre as partes e uma compatibilização entre fôrças em conflito, o que já é uma boa contribuição para superar certos problemas de estrutura.

O autor do artigo aceita a crítica de que "limitou-se a apresentar os instrumentos, sem contudo analisar-lhes as potencialidades e limitações". Como já disse, sendo experimental êsse nôvo tipo de estrutura, ainda não há dados que permitam uma avaliação mais profunda.

A nova CONJUNTURA ECONOMICA permanece tradicional. E ainda objetiva, precisa, imparcial e atualizada. Tudo como antes. Ficou, é claro, mais bonita, moderna, e seu formato é maior. Para facilitar as consultas e tentar, depois, o leitor a deixá-la em cima da mesa, só para enfeitar.

Uma publicação da Fundação Getúlio Vargas. Procure nas bancas ou escreva para a Praia de Botafogo 188, Caixa Postal 21.120, ZC-05, Rio de Janeiro, GB. 